\title{
Ophthalmologica
}

Ophthalmologica 2015;233:58-59

DOI: $10.1159 / 000365789$
Received: May 28, 2014

Accepted: July 3, 2014

Published online: November 26, 2014

\section{The Centennial of Modern Gonioscopy}

\author{
Anamika Tandon Wallace L.M. Alward \\ Department of Ophthalmology and Visual Sciences, University of lowa Carver College of Medicine, \\ lowa City, lowa, USA
}

The year 2014 is the 100th anniversary of modern gonioscopy. The first paper on the subject was published in 1914 in the journal Zeitschrift für Augenheilkunde, the predecessor of Ophthalmologica.

While Alexios Trantas, a Greek ophthalmologist, obtained the first view of the iridocorneal angle in a living human in 1898 , his technique employed direct ophthalmoscopy and scleral indentation with his finger [1]. Trantas was most interested in viewing the ciliary body; the view of the trabecular meshwork was an incidental discovery. Modern gonioscopy with a contact lens was described 100 years ago by Maximilian Salzmann. His landmark papers were published in 1914 and 1915 [2,3].

Salzmann recognized the concept of total internal reflection and used a Fick lens to overcome this reflection and achieve a direct view of the iridocorneal angle [3]. The Fick lens was a highly convex contact lens designed to treat keratoconus. Besides being a brilliant ophthalmologist, Salzmann was a remarkably skilled artist. The 42 paintings in his seminal papers contained beautiful detail that should humble modern ophthalmologists, who have access to much more sophisticated equipment. Four examples of his artwork are re-

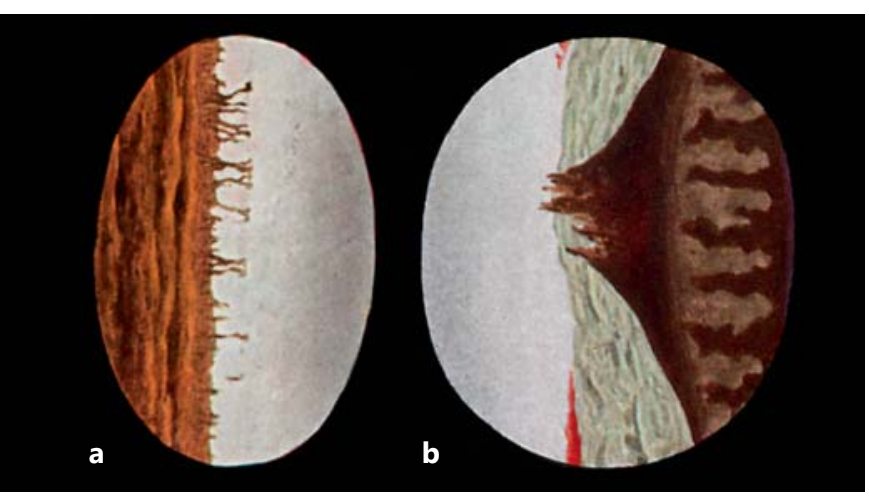

Fig. 1. Figures from Salzmann's papers from 1914 and 1915. a 'Normal angle with prominent iris extensions, inverted image, Maria PL. 29 y/o, left eye.' b 'Left eye, temporal quadrant, male, $37 \mathrm{y} / \mathrm{o}$, small rupture of the corneo-scleral border (case XIV). Displacement of the iris due to vitreous (falling forward) and radial tear, corona cilliaris.' c 'Left eye, temporal-inferior quadrant; male, 19 y/o, contusion bulbi (case XII). Circumscribed exten-

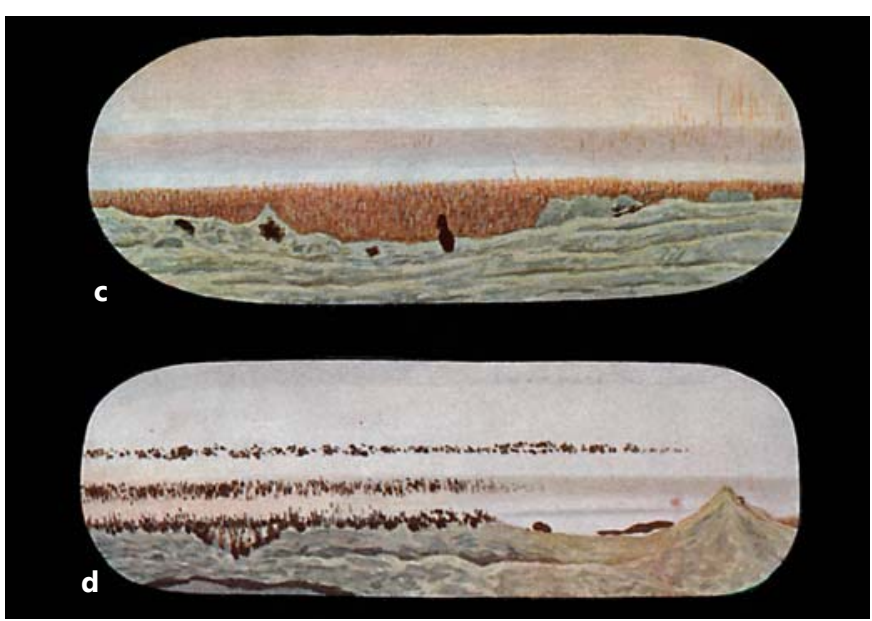

sion/enlargement of the angle, remains of an ecchymosis.' d 'Right eye, inferior and temporal-temporal portion, male, 37 y/o, traumatic cataract, (case VII), goniolens. Circumscribed and incomplete peripheral synechiae, pigmentation of the trabecular meshwork.' The descriptions were translated from Salzmann by Markus H. Kuehn, PhD.

\section{KARGER 125}

2014 S. Karger AG, Basel

$0030-3755 / 14 / 2331-0058 \$ 39.50 / 0$

E-Mail karger@karger.com

www.karger.com/oph
Wallace L.M. Alward, MD

Department of Ophthalmology and Visual Sciences

University of Iowa Carver College of Medicine, 200 Hawkins Drive

Iowa City, IA 52242-1091 (USA)

E-Mail wallace-alward@uiowa.edu 
produced here (fig. 1). All of his angle paintings are reproduced, with permission from S. Karger AG, on the gonioscopy.org website (http://gonioscopy.org/index.php? option $=$ com_k2\&view $=$ item\&id $=28$ ).

Sadly, despite advances in the ease of gonioscopy over the last century, gonioscopy is still performed less commonly than it should be. Fremont et al. [4] studied pat- terns of care for open angle glaucoma in the US and found that only $45.9 \%$ of new patients had gonioscopy performed during their initial evaluation.

We should let Salzmann's remarkable paintings spur us to dust off our gonioscopy lenses and look at the anterior chamber angle more frequently.

\section{References}

1 Trantas A: L'ophtalmoscopie de l'angle iridocornéen (gonioscopie). Arch Ophtalmol (Paris) 1918;36:257-276.

2 Salzmann M: Die Ophthalmoskopie der Kammberbucht. Z Augenheilk 1914;31:1-19.

-3 Salzmann M: Nachtrag zu Ophthalmoskopie der Kammerbucht. Z Augenheilk 1915;34: 160-162.

$\checkmark 4$ Fremont AM, Lee PP, Mangione CM, Kapur K, Adams JL, Wickstrom SL, Escarce JJ: Patterns of care for open-angle glaucoma in managed care. Arch Ophthalmol 2003;121: 777-783. 